\title{
Lateral Ulnar Collateral ligament Lesions in patients with Lateral Epicondylitis: MR Imaging Findings.
}

\author{
Mohamed Farouk Aggag*and Ragy Tantawi Amin** \\ *Radio diagnosis Department, El Azhar University, ** Rheumatology \\ and Rehabilitation Department, El Azhar University
}

\begin{abstract}
:
Objective. The aim of this work was to determine if a correlation between lateral epicondylitis and abnormalities of the lateral ulnar collateral ligament is found on MR imaging.

Subjects and Methods. The Study group comprised 50 consecutive patients who were referred for MR imaging to rule out lateral epicondylitis. On MR imaging "lateral epicondylitis" was defined as increased signal intensity of the extensor tendons close to their insertion on the lateral epicondylitis. The severity of the lateral epicondylitis was graded as mild, moderate or severe. The origin of the lateral colleteral ligamantous complex was characterized and the lateral ulnar collateral ligament was normal, thickened, partially torn or torn. Sixteen patients underwent elbow surgery after the initial MR examination.
\end{abstract}

Results. In 15 patients, MR imaging revealed characteristics of mild lateral epicondylitis. In 13 of these patients the lateral ulnar collateral ligament was normal. One patient showed a thickened lateral ulnar collateral ligament and one patient had a thinned ligament.

In 17 patients, MR imaging showed features of moderate lateral epicondylitis. One patient had a thinned ligament feature of moderate lateral epicondylitis. In 14 of these patients, the lateral ulnar collateral ligament was thickened and in the remaining three patients, the ligament was normal

All eighteen patients with severe lateral epicondylitis showed abnormalities of the lateral ulnar collateral ligament on MR imaging.

In two of these patients, the lateral ulnar collateral ligament was thickened. In Six patients we saw a partial tear, and in the remaining ten patients we saw a complete tear of the ligament.

Conclusion. In our study, MR imaging features of lateral epicondylitis were offen associated with thickening and tear of the lateral ulnar collateral ligament and the frequency and severity of lateral ulnar collatered ligament lesions were directly related the severity (degree) of lateral epicondylitis.

\section{Introduction:}

Lateral epicondylitis, commonly known as (tennis elbow), is the most common cause of discomfort or disability of the elbow joint (Field L. D and Altchek $D W ; 1995)$.

Lateral epicondylitis commonly results from occupational or sports activities and activities of daily living that produce varus stress (Plancher KD et al; 1996). With over use or repetitive micro trauma, the origin of the common extensor tendon is thinned and partially avulsed at its insertion on the lateral epicondyle. In response to this partial avulsion, a scar tissue forms that is then susceptible to further tearing with repetitive trauma (Potter H.G. et al; 1995).

Epicondylitis, is typically diagnosed clinically and treated conservatively and imaging is not needed initially. When 
symptoms are resistant to medical management, however, further evaluation is needed, Sonography can be used as an initial imaging tool that might be adequate for diagnosing this condition in many patients and the sonographic features of lateral epicondylitis include outward bowing of the common extensor tendon, presence of hypo echoic fluid subjacent to the common tendon, thickening, decreased echogenicity and ill defined margins of the common tendon. MR imaging is reserved for patients with symptoms whose sonographic findings are normal (Miller $\mathbf{T T}$ et al; 2002).

It has been hypothesized that the same forces or mechanisms that lead to lateral epicondylitis may also produce associated lateral ulnar collateral ligament abnormalities, furthermore, injury to the lateral elbow ligamentous complex especially the Lateral ulnar collateral ligament may be responsible for therapy failure (Martin CE and Schweitzer ME; 1998).

\section{Aim of work}

The aim of this work is to determine if a correlation between lateral epicondylitis and abnormalities of the lateral ulnar collateral ligament is found on MR imaging.

\section{Materials and Methods: -}

During a 24 months period, we studied 50 Patients (15 women and 35 men, 20-50 years old) who were referred to the Radio diagnosis and Reumatology department of El Hussein Hospital for MR imaging of the Elbow to rule out lateral epicondylitis.

Their symptoms included local tenderness over the lateral epicondyle; pain in the extensor muscles induced by gripping or resistive extensor movements and localized lateral pain induced by weight bearing. The duration of symptoms ranged from 2 months and 1 Year (Table 1). None of these patients underwent corticosteroid injection within 3 months of the MR examination.
Sixteen patients subsequently underwent surgery. All patients included in this study underwent MR imaging of the elbow with a commercial elbow coil using a 1.5.T-magnet (Siemens 1.5 T). MR imaging was performed with the patient in the supine position, the elbow at the side, and fore arm in supination.

A standard protocol of the elbow was applied in all the examinations. The specific pulse sequences used were coronal, sagittal and axial T1- weighted spin echo (550/15 TR/TE), T2- weighted fast spin-echo with frequency selective fat presaturation (3000/60). Sagittal proton density weighted (3500/25) and coronal short inversion time inversion recovery (STIR) (3000/38TR/TE: $150 \mathrm{msec}$ inversion recovery time).

The slice thickness was $4 \mathrm{~mm}$, intersection gap was $1 \mathrm{~mm}$, field of view was $12 \mathrm{~cm}$, and the matrix size was 256 $\mathrm{x} 256$.

The MR images were evaluated prospectively at the time of the patients' initial presentation for tendinous and signal intensity changes and for morphologic alterations. The MR images were assessed for associated pathologic conditions such as degenerative bony and chondral lesions, joint effusions, and medial collateral ligament injuries.

"Lateral epicondylitis" was defined as abnormality of the uniform hypointense signal of the common extensor tendon and was graded as mild, moderate or severe.

"Mild epicondylitis" was defined as a thickened or thinned tendon with increased signal intensity. " Moderate epicondylitis" was defined as a partial - thickness tear, with thinning and focal disruption of the tendon that does not extend throughout the tendon, outlined by adjacent fluid. "Severe epicondylitis" was characterized as a fluidfilled gap separating the tendon from its insertion on the lateral epicondyle.

The origin of the lateral ligamentous complex was identified, and the lateral ulnar collateral ligament was evaluated. A thickened lateral ulnar collateral ligament was characterized by normal to increased signal intensity and thickening without interruption of the ligament. 
A partially torn ligament was characterized by thinning of the ligament with increased signal intensity within and surrounding the ligament.

A complete tear for the ligament was identified by a complete rupture and discontinuity of the fibers, with increased signal intensity. Changes in signal intensity and tendon morphology seen at MR imaging were correlated with surgical and histopathological findings in the 16 patients who underwent surgery.

\section{Results}

All the 50 Patients who presented with clinical findings of lateral epicondylitis and included in this study showed abnormalities on MR imaging.

Tendon morphology was most easily assessed on coronal and axial images. The extensor corpi redialis brevis tendon was involved in all 50 Patients and abnormal morphological and signal intensity were seen at the tendon origin of the humerous.

The lateral ulnar collateral ligament was identified extending from the postero inferior margin of the lateral epicondyle distally at the head of the radius and inserting on the postero lateral aspect of the ulna at the superior crest (Fig 1). The intact ligament was characterized as a regular cord like structure with low signal intensity on all pulse sequences (Fig $2 \mathrm{a}, \mathrm{b}, \mathrm{c}$ ). The coronal plane was most valuable for evaluation of the lateral ulnar collateral ligament, but the ligament was generally not seen on a single coronal image because of its oblique course.

T2 - weighted fast spin-echo images with fat saturation and STIR images were most helpful in identifying tendon and ligamentous abnormalities.

Of the 50 patients included in the study, 15 (table 2) showed MR imaging features of increased signal intensity and thickening of the extensor corpi radialis breves tendon (mild lateral epicondylitis). In 13 of these patients. The lateral ulnar collateral ligament showed normal thickness and signal intensity (Fig. 3). One patient showed a thickened lateral ulnar collateral ligament and in one patient the lateral ulnar collateral ligament was thinned. None of the 15 patients with mild lateral epicondylitis underwent surgery.

Of the 17 patients with moderate lateral epicondylitis, six patients underwent surgery. At surgery, the diagnosis of a partial tear of the extensor carpi radialis brevis tendon was confirmed in 5 patients and one patient showed a complete tear.

In two patients with abnormalities of the lateral ulnar collateral ligament on MR imaging, the ligament was found to be thickened and degenerated during Surgery. Three patients with a normal lateral ulnar collateral ligament on MR imaging showed a normal ligament at Surgery.

For one patient with MR imaging findings of a thickened lateral ulnar collateral ligament, the ligament was not mentioned in the surgical report.

A complete tear of the extensor carpi radialis brevis tendon (severe lateral epicondylitis) was seen in eighteen patients on MR imaging (Table 4) and ten of whom underwent surgery. All of these patients showed abnormalities of the lateral ulnar collateral ligament on MR imaging. In two patients the lateral ulnar collateral ligament was thickened (Fig.6). In six patients the ligament showed thinning with high-signal intensity in and around the ligament (partial tear) (Fig 7), and in ten patients the lateral ulnar collateral ligament showed a complete tear with a fluid filled gap in the ligament. In these patients proximal detachment and avulsion from the lateral epicondyle was observed and manifested as complete absence of the lateral ulnar collateral ligament on MR imaging (fig $8 \mathrm{a}, \mathrm{b}$ ).

Of the ten patients with MR imaging findings of a complete tear of the extensor tendon who underwent surgery eight patients showed a complete tear of the tendon and two patients showed a partial tear of the extensor tendon during Surgery. For six patients with MR imaging finding of a complete tear of the lateral ulnar collateral ligament, the diagnosis was confirmed at surgery. Three patients with MR imaging findings of a partial tear of the lateral ulnar collateral ligament showed laxity of the ligament at Surgery. For one 
patient with a partial Tear of the lateral ulnar collateral ligament on MR imaging, the ligament was not mentioned in the surgical report.

Of the 50 patients included in this study, 12 patients had an isolated tendon or ligamentous abnormality without other elbow disorders. The remaining patients showed degenerative bony spurring (15 patients), joint effusions (10 patients), cartilage defects (7 patients), and abnormalities of the common externsor tendons (4 patients), while two patients showed bone marrow edema in the lateral epicondyle at the attachment site.

Table (1): Clinical picture of the 50 patients included in the study

\begin{tabular}{|c|c|c|c|c|c|c|c|c|c|}
\hline $\begin{array}{c}\text { Clinical } \\
\text { picture }\end{array}$ & \multicolumn{2}{|c|}{$\begin{array}{c}\text { Age } \\
<30>30\end{array}$} & \multicolumn{2}{|c|}{ Sex } & \multicolumn{2}{|c|}{$\begin{array}{c}\text { Duration of } \\
\text { symptoms }\end{array}$} & \multicolumn{2}{c|}{ Symptoms } \\
\cline { 2 - 9 } & & & & $\begin{array}{c}\text { Less } \\
\text { than 6 } \\
\text { months }\end{array}$ & $\begin{array}{c}\text { More } \\
\text { than 6 } \\
\text { months }\end{array}$ & $\begin{array}{c}\text { Local tenderness } \\
\text { over the lateral } \\
\text { epicondyle }\end{array}$ & $\begin{array}{c}\text { Pain in the extensor } \\
\text { muscles induced by } \\
\text { gripping or resistive } \\
\text { extensor }\end{array}$ & $\begin{array}{c}\text { Localized lateral } \\
\text { pain initiated by } \\
\text { weight bearing }\end{array}$ \\
\hline $\begin{array}{c}\text { Number of } \\
\text { Patients }\end{array}$ & 32 & 18 & 35 & 15 & 22 & 28 & 15 & 18 & 17 \\
\hline
\end{tabular}

Table (2): MR imagining findings of Lateral ulnar collateral ligament in mild lateral epicondylitis

\begin{tabular}{cccc}
\hline $\begin{array}{c}\text { MR imaging finding of } \\
\text { Lateral ulnar collateral } \\
\text { ligament in mild epicondylitis }\end{array}$ & $\begin{array}{c}\text { Normal thickness and } \\
\text { signal intensity }\end{array}$ & Thinned & thickened \\
\hline Number of Patients & 13 & 1 & 1 \\
\hline
\end{tabular}

Table (3): MR imaging findings of lateral ulnar collateral ligament in moderate lateral epicondylitis

\begin{tabular}{|l|c|c|}
\hline $\begin{array}{l}\text { MR imagingins of lateral ulnar collateral } \\
\text { ligament in moderate later epicondylitis }\end{array}$ & $\begin{array}{l}\text { Thickened lateral ulnar } \\
\text { collateral ligament }\end{array}$ & $\begin{array}{l}\text { Normal thickness and } \\
\text { signal intensity }\end{array}$ \\
\hline Number of Patients & 14 & 3 \\
\hline
\end{tabular}

Table (4): MR imaging finding of lateral ulnar collateral ligament in Server lateral epicondylitis

\begin{tabular}{|l|c|c|c|}
\hline $\begin{array}{l}\text { MR imaging findings of lateralulnar } \\
\text { collateral ligament is Severe lateral } \\
\text { epicondylitis }\end{array}$ & Thickened & Partiel Tear & Complete tear \\
\hline Number of patients & 2 & 6 & 10 \\
\hline
\end{tabular}




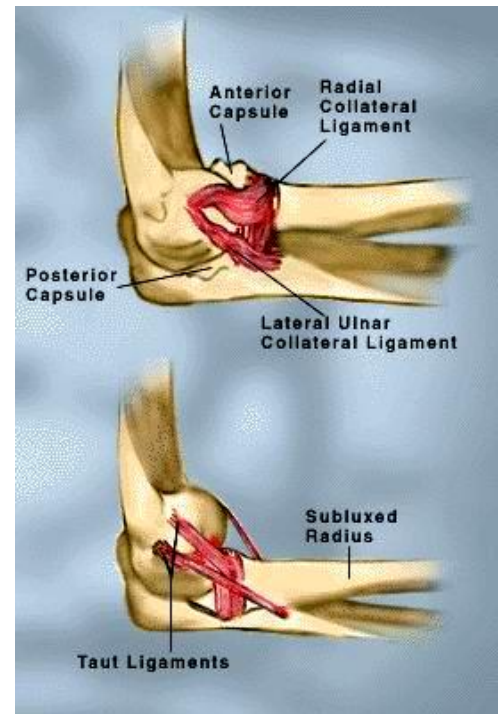

Fig. (1): Normal Anatomy

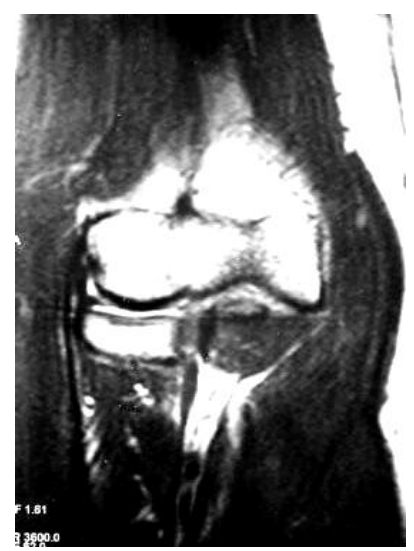

A

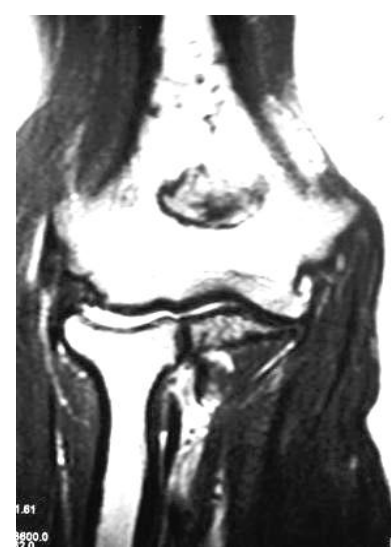

B

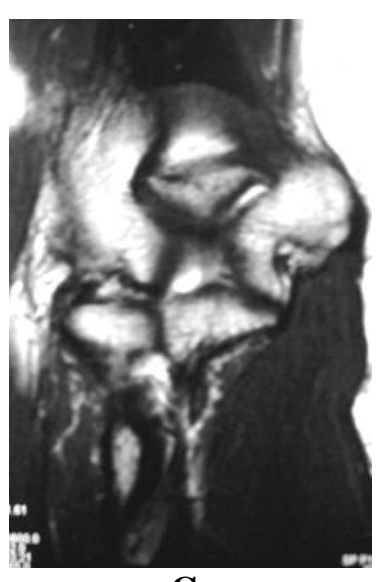

C

Fig. (2): A and B Coronal T2 weighted fast spin-echo-images reveal normal thickness and intensity of common extensor tendon. C. image shows normal thickness and signal intensity at origin of lateral ulnar collateral ligament (LUCL).

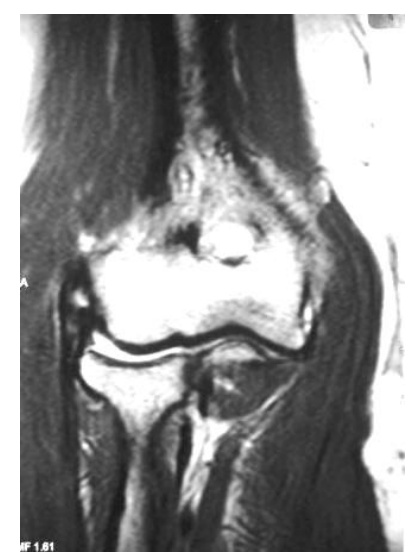

Fig. (3): Coronal T2 weighted fast spin-echo-image reveals focus of increased signal intensity in common extensor tendon, consistent with mildly epicondylitis, normal thickness and signal intensity at origin of LUCL. 


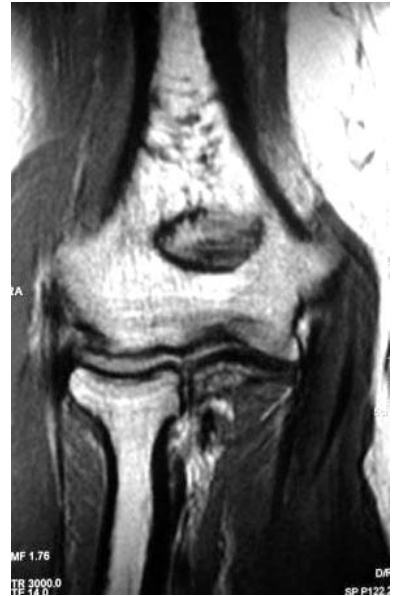

Fig. (4): A

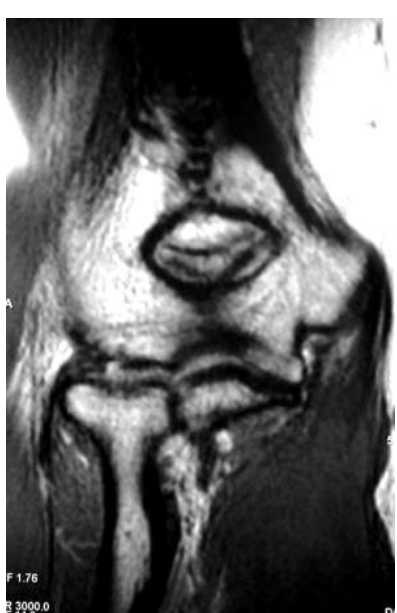

B

Fig. (4) A, B, Coronal T2 weighted fast spin-echo-images reveals increased signal intensity of common extensor tendon compatible with partial tear and consistent with moderate epicondylitis, the underlying LUCL is normal.

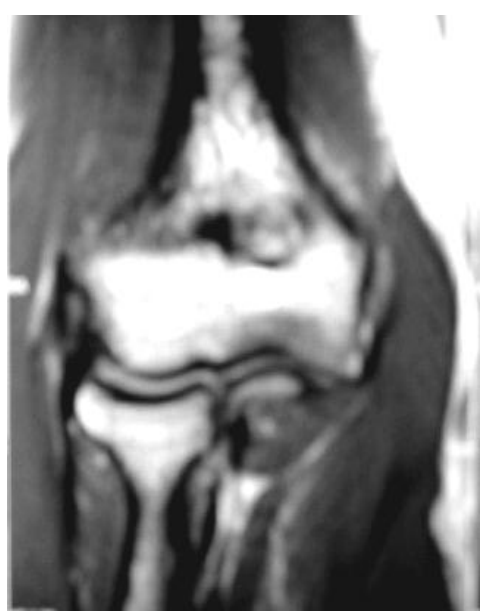

Fig. (5)

Fig. (5): Coronal T2 weighted fast spin-echo-image reveals partial tear of common extensor tendon consistent with moderate epicondylitis, the underlying LUCL is thickened.

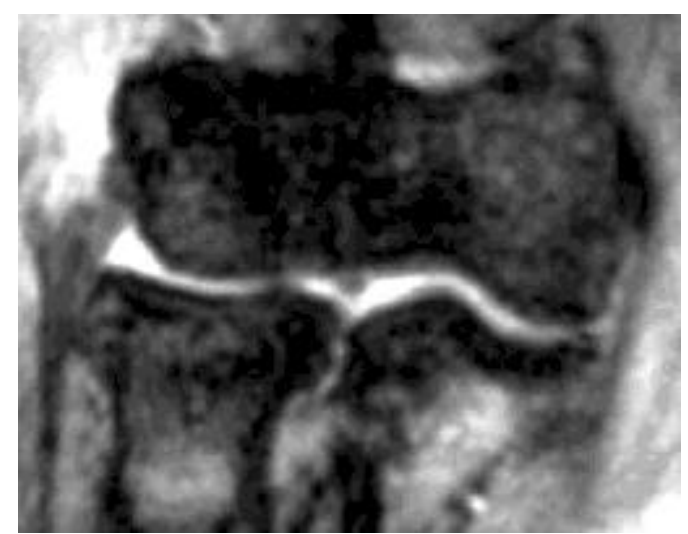

Fig. (6)

Fig. (6): Coronal T2 weighted fast spin-echo with fat saturation image reveals complete tear of common extensor tendon, consistent with severe epicondylitis, the underlying LUCL is thickened. 


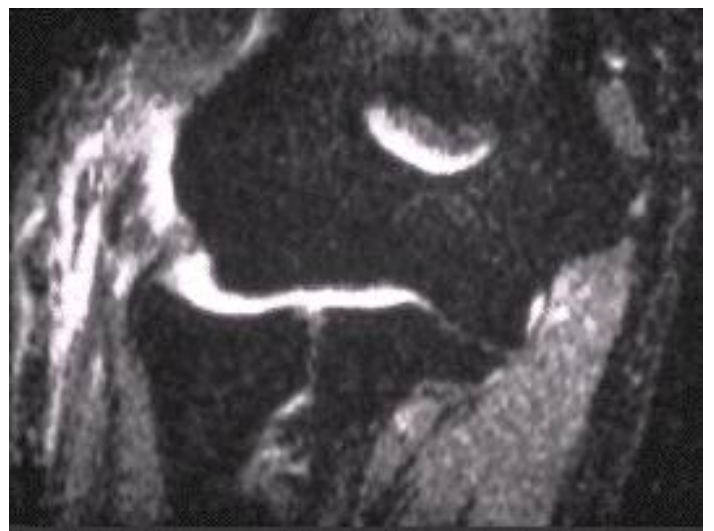

Fig. (7)

Fig. (7): Coronal T2 weighted fast spin-echo with fat saturation image reveals complete tear of common extensor tendon, consistent with severe epicondylitis, partial tear of underling LUCL.

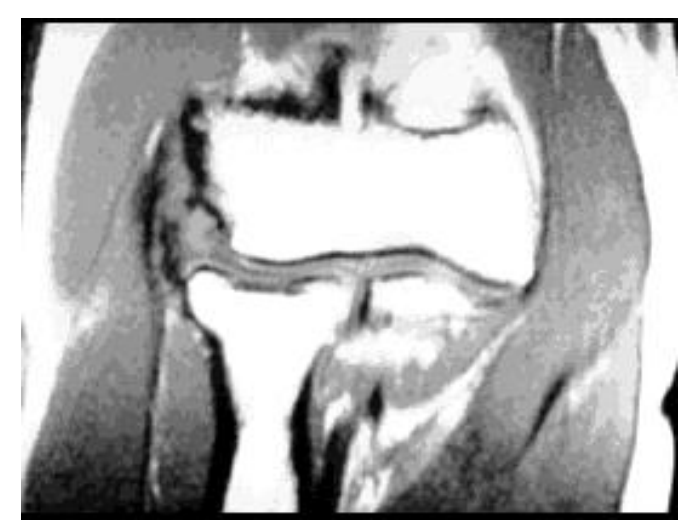

Fig. (8) A

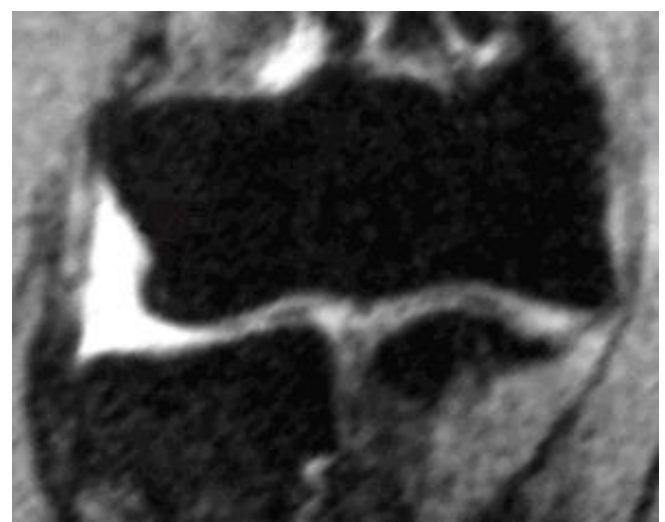

B

Fig. (8): A. coronal T1 weighted spin-echo image reveals complete tear of common extensor tendon, the origin of LUCL is completely detached from lateral epicondyl. $\quad$ B. Coronal T2 weighted fast spin-echo with fat saturation image reveals complete tear with fluid filled gap in the ligament consistent with severe epicondylitis

\section{Discussion:}

Tendon injuries are among the more common sources of elbow pain, resulting from occupational and sports activities as well as activities of daily living (Ho $\boldsymbol{C P}$ 1997).

Recent clinical experience has shown MR imaging to provide useful information in detecting, assessing and characterizing sports related disorders of the elbow due to its accurate depiction of structures (muscles, ligaments and tendons), direct visualization of nerves, bone marrow and hyaline cartilage and its ability to detect the extent of bone and soft tissue pathology (Fritz RC; 1999).

The common extensor origin (CEO) is confirmed as the primary site of MRI changes in tennis elbow (Mackay D et al; 2003), where lateral epicondylitis primarily involves the origin of the extensor carpi radialis brevis tendon and is caused by repetitive stress resulting in mucoid degeneration and reactive granulation of the tendon. Pathologically the involved tendons are characterized by collagen fibrillar degeneration, angio fibroblastic proliferation, tissue necrosis with myxoid and hyaline degeneration, fibrosis and occasional inflammatory cells (Regan W. et al; 1992).

The patient with tennis elbow most commonly presents for evaluation and treatment of pain rather than mechanical functional disability. The conservative 


\section{Mohamed Farouk Aggag \& Ragy Tantawi Amin}

treatment for lateral epicondylitis includes anti-inflammatory drugs, steroid injection, physiotherapy or immobilization. Approximately $90-95 \%$ of patients respond to conservative therapy (Plancher KD et al; 1996)

For patients in whom conservative treatment regimens fail, several surgical options are available for the treatment of lateral epiconylitis, release of the common extensor tendon, debridement of the origin of the extensor carpi radialis brevis with release of the annular ligament, and excision of the degenerated tissue with reattachment of the origin of the extensor carpi radialis brevis (Field ZD. and Altchek DW. 1995).

However, further examination may be necessary in these patients to assess the degree of tendon disease and to evaluate other causes of treatment failure.

One cause of therapy-resistant lateral epiconylitis can be lateral ligamentous injury (Fritz $R C$ et al; 1997). Repeated micro trauma and over loading of the lateral ligamentous complex can cause microscopic tears and resulting inflammatory degeneration. As a result of this damage, the ligament is weakened and predisposed to rupture, which may result in postero lateral rotatory instability $\left(\boldsymbol{O}^{\prime}\right.$ Driscoll $S W$ et al; 1991).

Unsuspected ruptures of the lateral ulnar collateral ligament may occur in association with tears of the common extensor tendon (Nirschal RP; 1992). When rupture of the lateral ulnar collateral ligament and subtle instability is not recognized preoperatively, surgical release of the extensor tendon may further destabilize the elbow (Morrey BF; 1993).

In our study, lateral ulnar collateral ligament injuries were commonly associated with lateral epicondylitis especially with moderate and severe degrees of Lateral epicondylits. Thirty-four (70\%) of 50 Patients with lateral epicondylitis showed abnormalities of the lateral ulnar collateral ligament on MR imaging.

Of the 15 patients who showed MR imaging features of increased signal intensity and thickening of the extensor carpi radialis brevis tendon (mild lateral epiconylitis), only two patients showed MR abnormalities of the lateral ulnar collateral ligament, where in one Patient this ligament was thickened while in the other patient it was thinned out

On the other hand, partial thickness tears of the extensor carpi radialis brevis tendon (mederate epicondylitis) were diagnosed in 17 patients on MR imaging. In 14 of these patients thickened lateral ulnar collateral ligament was noted.

A complete tear of the extensor carpi radialis brevis tendon (severe lateral epicondytilis) was seen in 18 cases on MR imaging. All of these patients showed abnormalities of the lateral ulnar collateral ligament on MR imaging, where in two patients this ligament was thickened, in six patients the ligament was thinned out with high signal intensity in and around the ligament (partial tear) while in ten patients, the lateral ulnar collateral ligament showed a complete tear with a fluid gab in the ligament and in these patients, proximal detachment and avulsion from the lateral epicondyle was observed and manifested as complete absence of the lateral ulnar collateral ligament on MR imaging

We found that MR imaging is useful in detecting and characterizing the degree of tendon and associated lateral ulnar collateral ligament degeneration and tearing in patients with lateral epicondylitis. In addition to determining the degree of tendon and ligament damage, MR imaging may provide a global assessment of the elbow and therefore reveal additional disorders that may be responsible for a lack of therapeutic response in patients with lateral epicondylitis.

In conclusion, MR imaging of patients with lateral epicondylitis should be carefully evaluated for abnormalities of the lateral ulnar collateral ligament, especially if surgical release of the common extensor tendon is proposed in cases with no response to the conservative therapy.

\section{References}

1. Field LD. Altchek DW. Elbow injuries. Clin sports Med 1995; 14:59-78 
2. Fritz RC, Steinbach LS, Tirman RF, Martinez S. MR imaging of the elbow: an update. Radiol Clin North Am 1997; 35: 117-114

3. Fritz RC. MR imaging of sports injuries of the elbow. Magn Reson Imaging Clin N Am. 1999 Feb; 7(1) 51-72

4. Ho Cp. MR imaging of tondon injuries in the elbow. Magn Resen Imaging Clin N Am. 1997 Aug; 5 (3); 529-43

5. Machay D, Rangan A, Hide G, Hughest, Latimer J. The objective diagnosis of early tennis elbow by magnetic resonance imaging. Ocup Med (Lond). 2003 Aug; 53 (5): 309-12

6. Martin CE, Schweitzer ME. MR imaging of epicondylitis. Skeletal Radiol 1998; 27: 133-138

7. Miller TT, Shapiro MA, Schultz E, Kalish. Comparison of Sonography and MRI for diagnosing epicondylitis. J Clin Ultrasound. 2002 May; 30(4): 193202

8. Morrey BF. Surgical failure of the Tennis elbow. In: Morrey BF, ed.
Ed. The elbow and its disorders. Philadelphia: Saunders 1993; 553559

9. Nirschl RP. Elbow tendinosis/ tennis elbow. Clin Sports Med 1992; 11: 851-870

10. O' Driscoll SW, Bell DF, Morrey BF. Postero Lateral rotatory instability of the elbow. J Bone joint Surg Am 1991; 73-A: 440446

11. Potter HG, Hannafin JA, Morwessel RM, Dicarloef, and O'Brien SJ, Alt chek DW. Lateral epicondylitis:correlation if MR imaging, surgical, and histopathologic findings. Radiology 1995; 196: 43-46

12. Plancher KD, Halbrecht $\mathbf{J}$, Lourie GM. Medial and lateral epicondylitis in the athlete. Clin Sports Med 1996; 15: 283-305

13. Ragan W, Wold LE, Coorad R, Morrey BF. Microscopic histopathology of chronic refractory lateral epicondylitis. Am J Sports Med 1992; 20: 746749. 


\section{صور الرنين المغناطيسي فى اصابات الأربطة الجانبية للزندى فى مرض الاض التهاب المكحالان لمفصل المرفق}

* محمد فاروق عجاج ، ** راجى طنطاوى أمين

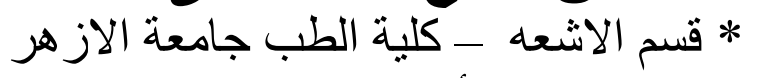

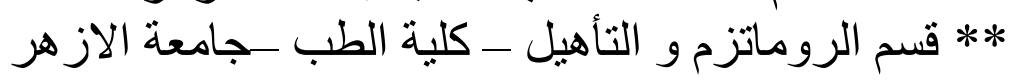

يعتبر التشخيص السليم للأربطة الجانبيـة للزندى فى مرض التهاب المكحالان

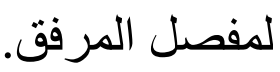
بحيث يمكن البدء فى العلاج الطبى و الجر احى العاجل و الملائم

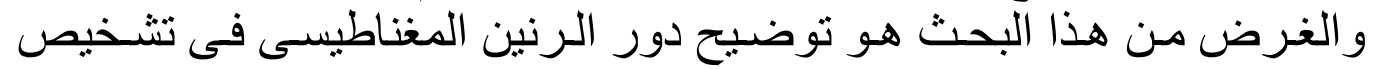

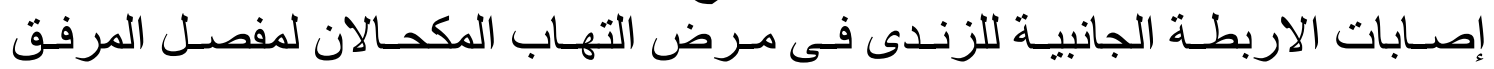

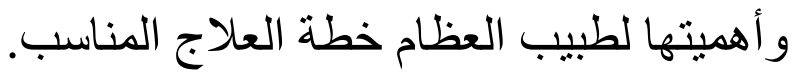

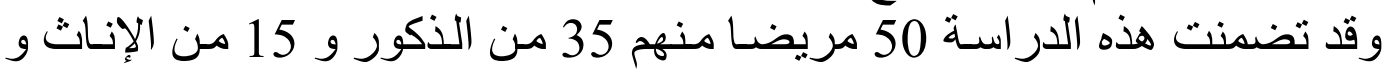

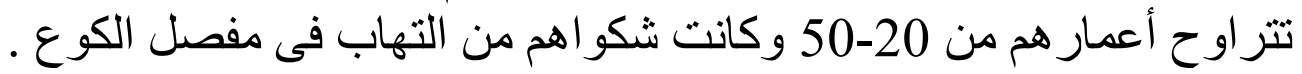

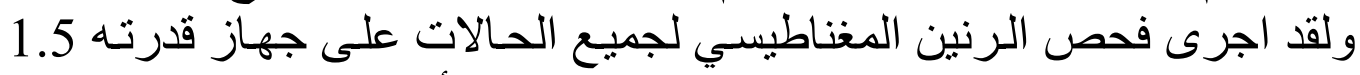

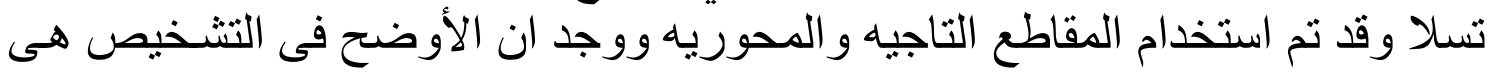

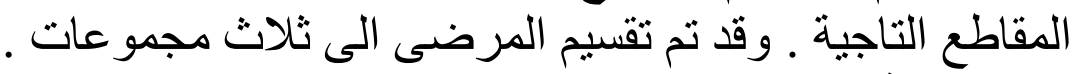

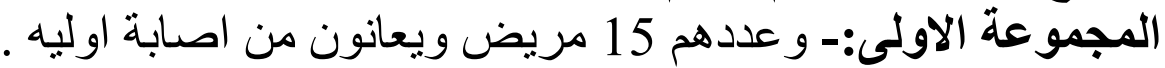

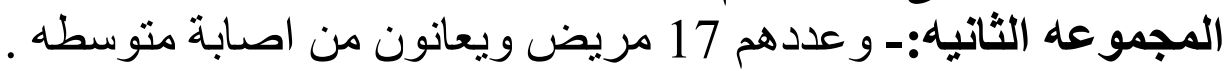

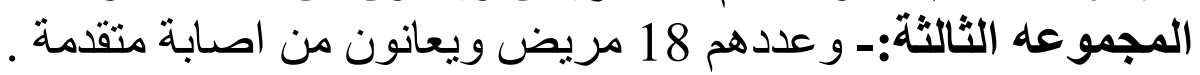

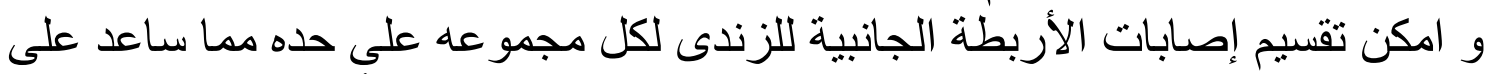

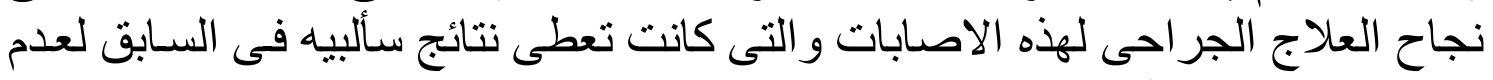
تقيم إصابات الاربطة الجانبية للزندى لمفصل الهابل المرفق. 